\title{
WHO Central Nervous System Grade IV
}

National Cancer Institute

\section{Source}

National Cancer Institute. WHO Central Nervous System Grade IV. NCI Thesaurus. Code C62397.

Describes central nervous system tumors that are generally highly malignant, show rapid and aggressive growth, widely infiltrative, and prone to necrosis. They often recur rapidly after treatment. 